\title{
Studies of Human C5a as a Mediator of Inflammation in Normal Human Skin
}

Kim B. Yancey, Carl H. Hammer, Liana Harvath, Lois Renfer, Michael M. Frank, and Thomas J. Lawley Dermatology Branch, National Cancer Institute, National Institutes of Health, Bethesda, Maryland 20205; Laboratory of Clinical Investigation, National Institute of Allergy and Infectious Diseases, National Institutes of Health, Bethesda, Maryland 20205; and Division of Blood and Blood Products, National Center for Drugs and Biologics,

Food and Drug Administration, Bethesda, Maryland 20205

\section{Abstract}

C5a is an 11,000-D fragment of the fifth component of complement (C5) with potent anaphylatoxic and leukocyte chemotactic activities. C5a is believed to play an important role in the pathophysiology of certain skin disorders and systemic diseases with cutaneous manifestations. However, there is very little known about the in vivo reactivity of C5a in man. In this study we examined the effects of intradermal injections of human C5a in 17 normal volunteers. C5a was prepared by interacting highly purified human $\mathrm{C} 5$ with zymosan bound alternative pathway $\mathbf{C} 5$ convertase under conditions resulting in consumption of $\sim 90 \%$ of the $\mathrm{C5}$ substrate. C5a produced in this manner was chemotactic for human neutrophils and monocytes $\left(0.5 \times 10^{-7}\right.$ to $\left.10^{-9} \mathrm{M}\right)$ and caused neutrophil aggregation and myeloperoxidase release (concentrations $\geq 10^{-10} \mathrm{M}$ ) in vitro. In vivo, C5a produced immediate wheal and flare reactions in all volunteers, and was active in doses as low as $1 \mathrm{ng}\left(10^{-13} \mathrm{~mol}\right)$. Intradermal testing with $20 \mathrm{ng}$ of C5a in eight volunteers produced a maximal mean wheal of $11.75 \mathrm{~mm}( \pm 0.80 \mathrm{~mm}$ SEM) $20 \mathrm{~min}$ after anaphylatoxin injection, and a maximal mean erythema of $62.50 \mathrm{~mm}( \pm 3.27$ mm SEM) 10 min after C5a administration. Reactions at C5a test sites were dose-related, associated with marked pruritus in some subjects, resolved without lesion formation, and were not associated with late phase reactions. In vivo testing revealed that human C5a was a more potent mediator of wheal and flare reactions than histamine, $\mathbf{4 8 / 8 0}$, human $\mathrm{C3a}$, or morphine sulfate. Skin biopsies from eight volunteers $20 \mathrm{~min}$ after intradermal injection of $\mathbf{2 0} \mathbf{n g}$ of $\mathrm{C5a}$ revealed a neutrophilpredominant perivascular infiltrate, endothelial cell edema, and sites of leukocytoclasis. Mast cell degranulation was observed on both light and electron microscopy of biopsies from C5a test sites. Although erythema at C5a injection sites was reduced by pretreating volunteers with hydroxyzine, whealing reactions and cellular infiltrates in biopsies were unaffected by this $\mathrm{H}_{1}$-antihistamine. Moderate doses of systemic corticosteroids did not alter clinical or histologic reactions at $\mathrm{C5a}$ injection sites in two volunteers. This study, using doses within the potential physiologic range of the anaphylatoxin, provides a comprehensive assessment of the effect of human C5a on normal human skin.

Address correspondence to Dr. Yancey, Dermatology Branch, Building 10, Room 12N238, National Institutes of Health, Bethesda, MD 20205.

Received for publication 3 April 1984 and in revised form 7 September 1984.

The Journal of Clinical Investigation, Inc.

Volume 75, February 1985, 486-495

\section{Introduction}

$\mathrm{C} 5 \mathrm{a},{ }^{1}$ the $11,000-\mathrm{D}$ complement fragment generated by $\mathrm{C} 5$ convertase cleavage of intact $\mathrm{C} 5$, is known to be a potent mediator of inflammation. Animal and in vitro studies have demonstrated that $\mathrm{C5a}$ is an anaphylatoxin, a spasminogen, an aggregator of neutrophils and platelets, and a mediator capable of inducing cellular release reactions from a variety of leukocytes $(1,2)$. C5a is also chemotactic for neutrophils, eosinophils, basophils, and monocytes $(1,2)$. Although C5a is rapidly converted to the less potent des Arg form by serum carboxypeptidase N (EC 3.4.12.7), C5a des Arg also demonstrates many important biologic activities $(3,4,5,6)$. For these reasons, C5a is recognized as an important mediator in the microenvironment of the inflammatory response. Specifically, it has been suggested that C5a may play a key role in the recruitment of effector cells and the associated tissue damage in disorders such as necrotizing vasculitis (7), adult respiratory distress syndrome (8), the bullous eruption of systemic lupus erythematosus (9), and a variety of immunologically mediated skin diseases (10).

The number of observations specifically regarding the biologic activity of $\mathrm{C5a}$ in man are very limited. Few studies have assessed the activity of this mediator in vivo in humans with intact endogenous regulators, vascular influences, and interacting cellular elements. In this study we have produced C5a by alternative pathway convertase cleavage of purified human $\mathrm{C5}$, biologically and immunochemically characterized human C5a prepared in this manner, and then studied in detail the clinical and histologic reactions produced by intradermal injection of $\mathrm{C} 5 \mathrm{a}$ in 17 normal volunteers. In addition, several pharmacologic agents commonly employed to treat various dermatologic and/or allergic disorders were tested for their ability to modulate cutaneous reactivity to human C5a.

\section{Methods}

\section{Preparation of human $\mathrm{C} 5$}

Human C5 was prepared from pooled, normal human plasma by the method of Hammer et al. (11). The final concentration of the purified human C5 was $1 \mathrm{mg} / \mathrm{ml}$ in phosphate-buffered saline (PBS) (M. A. Bioproducts, Walkersville, MD). Analysis of C5 prepared by this technique with sodium dodecyl sulfate polyacrylamide gel electrophoresis (SDS PAGE) (12) revealed a single band with a molecular weight of $200,000 \mathrm{D}$ on unreduced $7.5 \%$ gels and bands of $122,000 \mathrm{D}$ (C5 alpha chain) and 74,000 D (C5 beta chain) on reduced 7.5\% gels. No

1. Abbreviations used in this paper: $\mathrm{C} 5$, fifth component of complement; C5a, fragment of C5; EACA, epsilon aminocaproic acid; FMLP, $N$ formyl-methionyl-leucyl-phenylalanine; I.D., intradermal; SDS PAGE, sodium dodecyl sulfate polyacrylamide gel electrophoresis; ZX, activated zymosan. 
contaminants of the C5 preparation were seen on gels stained with either Coomassie Brilliant Blue or silver reagent (Bio-Rad Laboratories, Richmond, CA). Goat anti-human C5 antibody (1:50) staining of nitrocellulose sheets containing human $\mathrm{C} 5$ electrophoretically transferred from reduced SDS PAGE gels confirmed the presence and purity of the C5 alpha and beta chains in this C5 preparation. Purified human C5 radiolabeled with ${ }^{125} \mathrm{I}-\mathrm{Na}$ (Iodo-beads, Pierce Chemical Co., Rockford, IL) had a specific activity of $0.08 \mu \mathrm{Ci} / \mu \mathrm{g}$. Radiolabeled C5 $\left({ }^{125} \mathrm{I}-\right.$ C5) at a concentration of $180 \mu \mathrm{g} / \mathrm{ml}$ retained $80 \%$ of its specific functional activity in C5 hemolytic assay. Autoradiograms of ${ }^{125} \mathrm{I}-\mathrm{C} 5$ on reduced and unreduced $7.5 \%$ SDS PAGE gels revealed the same protein bands identified in SDS PAGE and immunoblot analysis of purified $\mathrm{C} 5$ and no other ${ }^{125} \mathrm{I}-\mathrm{C} 5$ fragments.

\section{Preparation of human C5a}

Human C5a was prepared from purified C5 with serum-activated zymosan. Zymosan A (Sigma Chemical Co., St. Louis, MO) was boiled in PBS containing $10 \mathrm{mM}$ EDTA for $15 \mathrm{~min}$, washed twice with PBS alone, and then incubated with normal human serum at a concentration of $5 \mathrm{mg} / \mathrm{ml}$ for $15 \mathrm{~min}$ at $37^{\circ} \mathrm{C}$. The activated zymosan (ZX) containing particle-bound $\mathrm{C} 5$ convertase was washed twice with $1 \mathrm{M}$ epsilon aminocaproic acid (EACA) (Sigma Chemical Co.) in sterile saline and then reacted with purified human $\mathrm{C} 5$ for $30 \mathrm{~min}$ at $37^{\circ} \mathrm{C}$. Varying amounts of $\mathrm{ZX}$ were assessed for $\mathrm{C} 5$ convertase activity by quantitating consumption of $\mathrm{C} 5$ substrate with functional hemolytic assays. Optimal consumption of $\mathrm{C} 5$ substrate (i.e., 87\% consumption) was achieved when the reaction ratio of ZX to C5 was $10 \mathrm{mg}: 34$ $\mu$ grams. This ratio was thus used to prepare C5a for this study. With this method of C5a production, the reaction of $\mathrm{ZX}$ with $\mathrm{C5}$ was completed by the addition of cold sterile saline and removal of $\mathrm{ZX}$ by centrifugation at $1,000 \mathrm{~g}$ for $8 \mathrm{~min}\left(4^{\circ} \mathrm{C}\right)$. The supernatant containing $\mathrm{C} 5 \mathrm{a}$ was sterile filtered in a $0.45-\mu \mathrm{m}$ filter unit (Millipore Corp., Bedford, MA) and stored at $-70^{\circ} \mathrm{C}$ in sterile polystyrene tubes before use.

\section{Immunochemical characterization of $Z X$-cleaved $C 5$}

SDS PAGE. ZX-cleaved C5 was examined by SDS PAGE on reduced 7.5 , 9, and $12 \%$ gels stained with Coomassie Brilliant Blue or silver reagent (12).

Immunoblot. After SDS PAGE on reduced $12 \%$ gels, ZX-cleaved C5 was electrophoretically transferred to nitrocellulose paper and stained with a two-step immunoblot technique. In these experiments nitrocellulose sheets containing ZX-cleaved C5 were reacted sequentially with goat anti-human C5 antibody (1:50), horse radish peroxidase conjugated swine anti-goat IgG (1:400; Tago Inc., Burlingame, CA), and then developed with diaminobenzidine (Sigma Chemical Co.) and $\mathrm{H}_{2} \mathrm{O}_{2}$ (Fisher Scientific Co., Pittsburgh, PA). In control experiments, ZX-cleaved C5 samples on nitrocellulose sheets were reacted with normal goat serum (1:50) in place of the first step goat antibody listed above.

Gel filtration. ZX-cleaved C5 and ZX-cleaved ${ }^{125} \mathrm{I}$-C5 were chromatographed on Sephadex G-75 (1.5 $\times 90 \mathrm{~cm}$ column) (Pharmacia Fine Chemicals, Piscataway, NJ) in $0.1 \mathrm{M}$ ammonium formate, $\mathrm{pH}$ 5.0 , or $0.25 \mathrm{M} \mathrm{NaCl}, \mathrm{pH} 7.4$, column buffer. Individual gel filtration column fractions were monitored for the presence of C5a or ${ }^{125} \mathrm{I}-\mathrm{C} 5 \mathrm{a}$ with a polymorphonuclear cell (PMN) myeloperoxidase release assay and/or by following sample radioactivity (cpm). Selected column fractions containing C5a or ${ }^{125} \mathrm{I}-\mathrm{C} 5 \mathrm{a}$ were also tested in a standard chemotaxis assay as described below.

Autoradiography. Autoradiography of 7.5 and $12 \%$ SDS PAGE gels was used for analysis of ${ }^{125} \mathrm{I}-\mathrm{C} 5$, ZX-cleaved ${ }^{125} \mathrm{I}-\mathrm{C} 5$, and ${ }^{125} \mathrm{I}-\mathrm{C} 5 \mathrm{a}$.

Radioimmunoassays (RIA). Human C5a and C3a were quantitated by RIA (Upjohn Diagnostics, Kalamazoo, MI).

\section{Preparation of human $\mathrm{C} 3 \mathrm{a}$}

Human C3a was produced by trypsin cleavage of human C3 and then purified to homogeneity by gel filtration chromatography.

\section{Preparation of human peripheral blood leukocytes}

Human PMNs and mononuclear cells were obtained from the heparinized venous blood of normal volunteers using previously described techniques $(13,14)$.

\section{Chemotaxis assay}

Leukocyte chemotaxis, random migration, and chemokinetic migration were quantitated in a multiwell assembly as previously described (15). The data are presented as the mean of triplicate values from individual donors. The positive control used in each chemotaxis assay was $N$-formyl-methionyl-leucyl-phenylalanine (FMLP; Sigma Chemical Co.)

\section{PMN myeloperoxidase release}

The ability of test samples to induce PMN myeloperoxidase release in vitro was measured by the method of Webster and Henson (16). Samples in this colorimetric assay were scored for myeloperoxidase release visually and at OD 492 (Micro Plate Reader MR580, Dynatech Laboratories, Inc., Alexandria, VA). Control wells in each assay included Triton X (Packard Instrument Co., Inc., Downers Grove, IL), FMLP, and PBS. Control samples in this series of experiments included ZX-treated saline, purified human C5, sterile saline, and human C3a. All samples were tested in a blinded fashion.

\section{PMN aggregometry}

PMN aggregometry was performed according to the method of Hammerschmidt et al. (17). Results are expressed as the increment in light transmission on a relative scale.

\section{Subjects}

Human C5a was tested intradermally in 17 normal volunteers (8 females and 9 males, ages $19-45 \mathrm{yr}$, mean age $25.7 \mathrm{yr}$ ) after receiving their informed consent to protocol studies. All materials for injection were shown to be pyrogen and hepatitis B surface antigen-free before in vivo testing in humans (Pharmaceutical Development Division, National Institutes of Health, Bethesda, MD).

\section{Skin testing}

Intradermal skin tests were performed on the volar forearm of all 17 normal volunteers using insulin syringes (Monoject/Brunswick Company, St. Louis, MO) with 27-gauge needles. The injection volume of skin test reagents was $50 \mu \mathrm{l}$ unless otherwise specified. Millimeters of wheal and flare at skin test sites were recorded as the maximal reaction diameter observed at 5-min intervals after the intradermal injection of test materials. All acute phase reactions were followed to resolution; skin test sites were reinspected on several occasions within. $48 \mathrm{~h}$ of testing to check for the presence of any late phase or delayed reactions. C5a in sterile saline was tested intradermally in doses between 0.4 and $120 \mathrm{ng}$. In addition to being tested with C5a, volunteers were tested intradermally with ZX-treated saline-buffer control $(n=16)$, sterile saline alone $(n=17)$, histamine phosphate $(0.1-1.0 \mu \mathrm{g} ; n=2), 48 / 80$ (400 ng; $n=2)$, morphine sulfate ( $3 \mu \mathrm{g} ; n=2)$, and human C3a $(1-500 \mathrm{ng} ; n=2)$.

\section{Immunoadsorption studies}

Separate $1-\mathrm{ml}$ aliquots of $\mathrm{C} 5 \mathrm{a}(400 \mathrm{ng} / \mathrm{ml})$ were incubated with $0.2 \mathrm{ml}$ of Sepharose 4B (Pharmacia Fine Chemicals) bound with antibody directed against human C5a, Sepharose 4B bound with antibody directed against human C3a, or PBS-quenched Sepharose 4B alone for $1 \mathrm{~h}$ at $4^{\circ} \mathrm{C}$. These antisera were developed by immunizing goats with purified C5 or C3a, respectively. Antiserum specificity was tested by double diffusion and immunoelectrophoresis. Our $\mathrm{C5}$ antiserum recognizes native $\mathrm{C} 5$ and other $\mathrm{C} 5$ fragments, including $\mathrm{C} 5 \mathrm{a}$; this antiserum does not cross-react with $\mathrm{C} 3$ or its cleavage fragments. The $\mathrm{C} 3 \mathrm{a}$ antiserum used in control immunoadsorption experiments reacts with native $\mathrm{C} 3$ and $\mathrm{C} 3 \mathrm{a}$ without $\mathrm{C} 5$ or $\mathrm{C5a}$ cross-reactivity. Immunoadsorbent treated supernatants were millipore-filtered, and then $0.1 \mathrm{ml}$ of each 
sample (containing $40 \mathrm{ng}$ of C5a preimmunoadsorption) was tested for intradermal wheal and flare reactivity as described above.

\section{Skin biopsies}

3-mm punch biopsies of skin were obtained from 12 normal volunteers after intradermal testing with $\mathrm{C5a}$ and/or other reagents. Biopsies of test sites were obtained $20 \mathrm{~min}$ after intradermal injection unless otherwise specified and processed for two micron sections. In these studies, 1\% xylocaine without epinephrine (Astra Pharmaceutical Products, Inc., Worcester, MA) was used for local anesthesia after control biopsies showed that there were no alterations induced by this agent.

\section{Electron microscopy}

Skin biopsies of control and C5a injection sites (20 and $80 \mathrm{ng}$ of C5a in 0.05 and $0.1 \mathrm{ml}$, respectively) were also obtained from two normal volunteers for electron microscopy using circumferential/regional block anesthesia. Tissue sections (10 $\mathrm{nM})$ were examined with an electron microscope (400 T; Phillips Company, Holland).

\section{Pharmacologic modulation of skin reactivity to C5a}

Skin test reactions were recorded in two normal volunteers before and on the final day of treatment with an $\mathrm{H}_{\mathrm{i}}$-antihistamine (hydroxyzine $50 \mathrm{mg}$ per os, every $12 \mathrm{~h}$ for $2 \mathrm{~d}$ ). Two other normal volunteers were tested before and on the fifth day of receiving systemic corticosteroids (prednisone $15 \mathrm{mg}$ per os, four times daily for $5 \mathrm{~d}$ ). Both clinical and histologic reactions were assessed in these four normal volunteers.

Intradermal pretreatment of $\mathrm{C} 5 \mathrm{a}$ skin test sites with $1 \%$ xylocaine (2 mg, $n=1$ ) and terbutaline $(1,2,10$, and $20 \mu \mathrm{g}, n=1)$ was also performed to assess changes in cutaneous reactivity produced by local administration of these pharmacologic agents.

\section{Results}

\section{Immunochemical characterization of $Z X$-cleaved $C 5$}

SDS PAGE. SDS PAGE analysis of ZX-cleaved C5 revealed protein bands of the appropriate MW of albumin, C5 alpha, C5 alpha', and C5 beta chains on gels stained with Coomassie Brilliant Blue or silver reagent. Albumin was also identified in SDS PAGE analysis of the ZX-treated saline control reagent.

Immunoblot. Specific antibody staining of nitrocellulose sheets containing ZX-cleaved C5 electrophoretically transferred from reduced SDS PAGE gels precisely identified the C5 fragments listed above. C5a in the reaction mixture used for in vivo testing could not be identified on SDS PAGE gels or immunoblots due to its low concentration. However, under 10-fold concentrated reaction conditions, a band in the appropriate MW range of C5a (15,000 D) was seen on silver staining of SDS PAGE gels; the same band was specifically identified on immunoblots stained with anti-human C5.

Gel filtration. Purified human $\mathrm{C} 5$ and ${ }^{125} \mathrm{I}-\mathrm{C} 5$ chromatographed as a single protein peak on Sephadex G-75 gel filtration as determined by OD 280 and cpm, respectively. ZX-cleaved C5 and ZX-cleaved ${ }^{125} \mathrm{I}$-C5 revealed an additional protein peak in the low molecular weight range on column fraction analysis for PMN myeloperoxidase release and/or cpm, respectively (Fig. $1 \mathrm{~A}$ ). In these gel filtration experiments there was concordance of C5a biologic activity and the ${ }^{125} \mathrm{I}$ C5a chromatographic profile. In addition, column fractions containing C5a or ${ }^{125}$ I-C5a demonstrated chemotactic activity for human PMNs as described below.

Autoradiography. Autoradiography of reduced 7.5 and $12 \%$ SDS PAGE gels containing ${ }^{125}$ I-C5a purified by gel filtration and unfractionated ZX-cleaved ${ }^{125} \mathrm{I}-\mathrm{C} 5$ revealed a $15,000 \mathrm{D}$
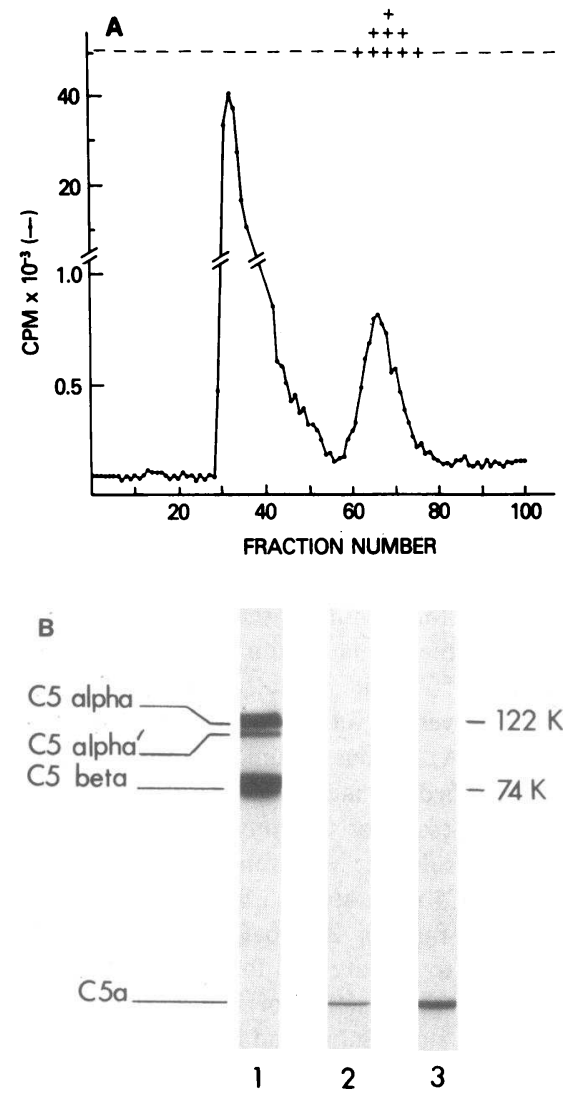

Figure 1. (A) Gel filtration chromatograph of ZX-cleaved ${ }^{125} \mathrm{I}-\mathrm{C} 5$ on Sephadex G-75 in $0.25 \mathrm{M} \mathrm{NaCl}, \mathrm{pH} 7.4$, and the corresponding bioassay profile of $\mathrm{C} 5 \mathrm{a}$-induced myeloperoxidase release from cytochalasin B-treated human PMNs. (B) This autoradiogram of an SDS PAGE gel demonstrates the C5 alpha, C5 alpha', C5 beta, and C5a (faint) bands in the ZX-cleaved ${ }^{125} \mathrm{I}-\mathrm{C} 5$ preparation (lane 1) as well as the solitary band of $\mathrm{C} 5 \mathrm{a}$ in a gel filtration column fraction containing the purified anaphylatoxin (lane 2). A commercially available

${ }^{125}$ I-C5a des Arg standard (Upjohn Co., Kalamazoo, MI) (lane 3) is included as a MW standard. (Note: the carbohydrate side chain at amino acid number 68 accounts for the anomalous migration of these 11,000-D proteins in SDS PAGE where they are found in the 15,000-D range [2].)

protein band that comigrated with an ${ }^{125} \mathrm{I}-\mathrm{C} 5 \mathrm{a}$ des Arg protein standard (Upjohn Diagnostics) (Fig. $1 B$ ).

RIAs. The concentration of human C5a in the ZX-cleaved C5 preparation was $955 \mathrm{ng} / \mathrm{ml}$. No C3a was detectable in the C5a preparation by specific RIA (sensitivity $\geq 1 \mathrm{ng} / 50 \mu \mathrm{l}$ ).

\section{Chemotaxis assay}

Using the microchemotaxis assay, C5a was chemotactic for human PMNs and monocytes at concentrations between 0.5 $\times 10^{-7}$ and $10^{-9} \mathrm{M}$ (Fig. 2). At C5a concentrations $\geq 10^{-7} \mathrm{M}$, PMN and monocyte chemotaxis was depressed indicating leukocyte desensitization to C5a. The total number of leukocytes migrating to optimal chemotactic concentrations of $\mathrm{C} 5 \mathrm{a}$ was similar to the total number of cells migrating to optimal concentrations of FMLP. Also, the chemotactic activity of C5a was significantly greater than its chemokinetic activity. Control samples of ZX-treated saline, saline alone, human C5, or human C3a were not chemotactic for PMNs or monocytes. 


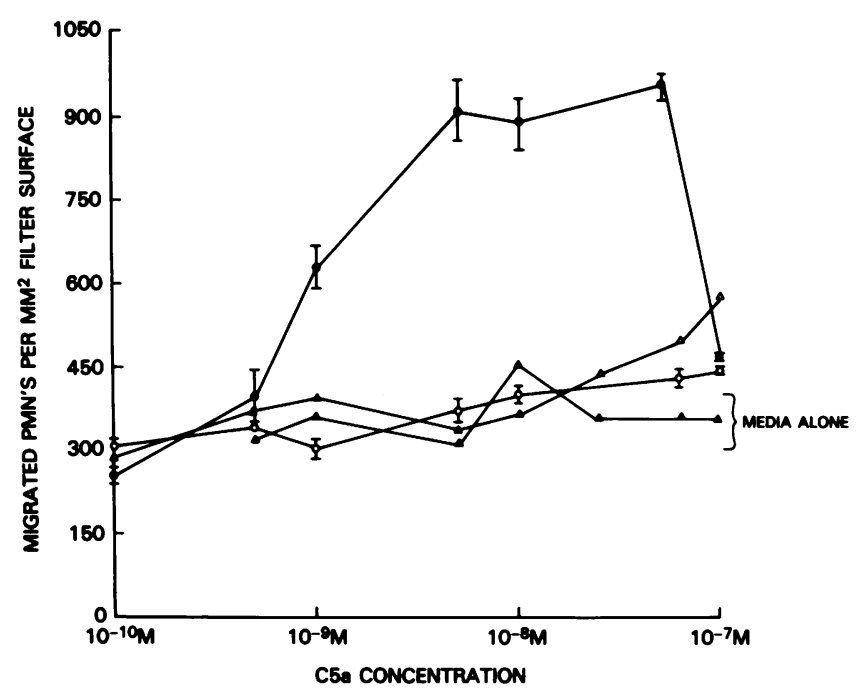

Figure 2. Human neutrophil chemotaxis to $\mathrm{C5a}$ and controls. —-, C5a; —०—, C5; — -, buffer; $-\Delta-$, ZXRx buffer.

\section{PMN myeloperoxidase release}

C5a elicited myeloperoxidase release from cytochalasin B pretreated PMNs at concentrations as low as $10^{-10} \mathrm{M}$. ZXcleaved C5 prepared without EACA treatment of activated zymosan (thereby allowing C5a to be cleaved to C5a des Arg) revealed no PMN myeloperoxidase release. There was also no PMN myeloperoxidase release when ZX-treated saline, saline alone, human $\mathrm{C} 5$, or $\mathrm{C} 3 \mathrm{a}$ were tested in this bioassay.

\section{Aggregometry}

C5a induced PMN aggregation at concentrations as low as $10^{-10} \mathrm{M}$. There was a direct dose response to $\mathrm{C} 5 \mathrm{a}$ in this assay system with increased PMN aggregation at higher concentrations of C5a. There was no PMN aggregation when ZX-treated saline, saline, or human C5 were tested in this assay system.

\section{Skin tests}

All 17 normal volunteers tested intradermally with C5a developed immediate wheal and flare reactions (Fig. 3). Reactions began immediately after C5a injection, were dose-related, and were associated with pruritus in 6 volunteers; 11 volunteers remained completely asymptomatic. No subjects complained of pain associated with C5a skin tests. Doses as low as $1.0 \mathrm{ng}$ $\left(10^{-13} \mathrm{~mol}\right)$ of C5a produced wheal and flare reactions in two of two volunteers; doses lower than $10 \mathrm{ng}$ produced wheal and flare reactions of less intensity and duration. Intradermal testing with $120 \mathrm{ng}$ of $\mathrm{C} 5 \mathrm{a}(0.1 \mathrm{ml})$ in one volunteer produced erythema, edema, and induration that lasted $4 \mathrm{~h}-\mathrm{a}$ reaction longer than that observed in volunteers tested with lower doses of anaphylatoxin. Intradermal testing with $20 \mathrm{ng}$ of $\mathrm{C} 5 \mathrm{a}$ in eight volunteers revealed maximal mean whealing reactions of $11.75 \mathrm{~mm}( \pm 0.80 \mathrm{~mm}$ SEM) $20 \mathrm{~min}$ after C5a injection. The maximal mean flare in these same subjects was observed 10 min after C5a injection and averaged $62.50 \mathrm{~mm}( \pm 3.27 \mathrm{~mm}$ SEM) in diameter (Fig. 4). Pseudopods formed at the margins of C5a whealing reactions in 14 volunteers; pallor was seen overlying the central portion of whealing reactions in subjects tested with C5a. All C5a injection studies were carefully controlled by also testing volunteers intradermally with $\mathrm{ZX}$ - treated sterile saline and sterile saline alone. The negligible reactions that occurred at these control injection sites were the same and represented background skin reactivity (Figs. 3 and 4). Purified human $C 5$ incubated with unactivated zymosan $(34 \mu \mathrm{g}: 10 \mathrm{mg}$ ) free of $\mathrm{C} 5$ convertase activity was also negative in control skin test experiments.

To assess C5a reactivity in vivo under conditions of continuous infusion, $80 \mathrm{ng}$ of $\mathrm{C} 5 \mathrm{a}$ in $0.5 \mathrm{ml}$ of sterile saline was administered intradermally to the thigh of a normal volunteer over $2 \mathrm{~h}$ with an infusion pump (Auto Syringe, Hooksett, NH). Local pruritus was noted for the first $40 \mathrm{~min}$ of this infusion and then resolved. Wheal and flare were observed at the infusion site but these reactions were less than those recorded after bolus intradermal injections of $2.5 \mathrm{ng}$ of $\mathrm{C5a}$ in the same volunteer. No late phase reactions were observed at any C5a test sites in these normal volunteers.

The in vivo intradermal reactivity of human C5a was directly compared with histamine, $48 / 80$, human C3a, or

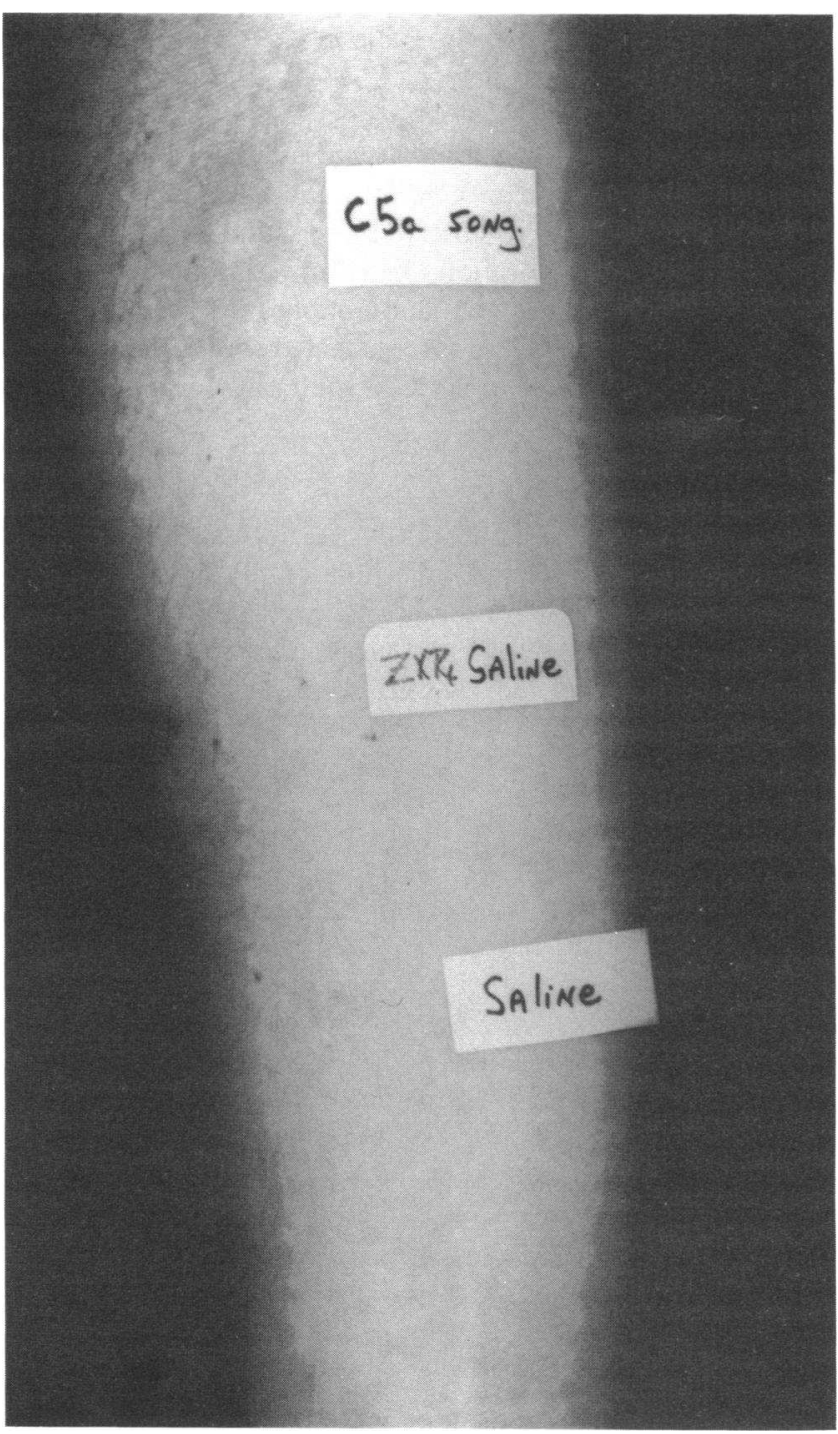

Figure 3. Skin test reactions 20 min after the intradermal injection of $20 \mathrm{ng}$ of C5a. No wheal and flare reactivity is apparent at control injection sites tested with equivalent volumes of ZX-treated sterile saline or saline alone. 


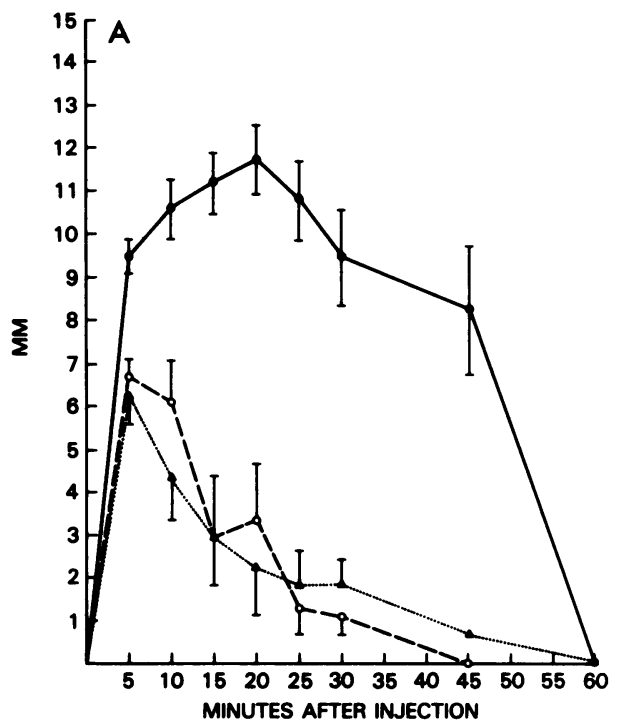

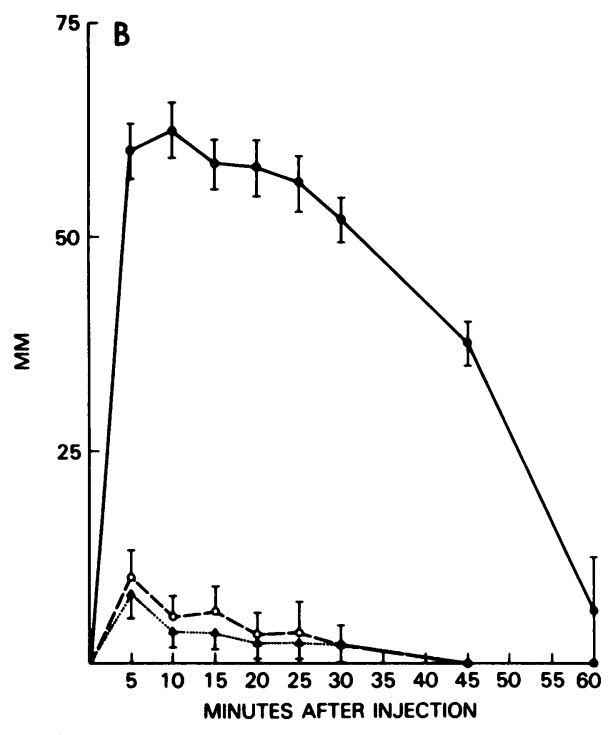

Figure 4. Diameters of wheal $(A)$ and flare $(B)$ in eight normal volunteers tested intradermally with 0.05 $\mathrm{ml}$ containing $20 \mathrm{ng}$ of $\mathrm{C} 5 \mathrm{a}, \mathrm{ZX}$ treated saline, or saline alone. - - , C5a $20 \mathrm{ng}$; - ०-, ZXRx saline; $\cdots . \cdots$, saline. morphine sulfate in a group of normal volunteers. Results of these studies are presented in Table $\mathrm{I}$.

\section{Immunoadsorption studies}

C5a was also tested intradermally after it was incubated with a solid phase anti-human C5a immunoadsorbent. No wheal and flare reactions were observed after intradermal injection of this C5a-free preparation. In control immunoadsorption experiments, there was no diminution in wheal and flare reactions to $\mathrm{C5a}$ preparations incubated with Sepharose $4 \mathrm{~B}$ alone, or with an anti-human $\mathrm{C} 3 \mathrm{a}$ solid phase immunoadsorbent.

\section{Skin biopsies}

Skin biopsies were obtained from 12 normal volunteers 20 min after the intradermal injection of $20 \mathrm{ng}$ of C5a. All biopsies demonstrated a pronounced perivascular infiltrate of PMNs, mononuclear cells, and eosinophils in the superficial and mid-dermis. Leukocytes were seen invading blood vessel walls and the adjacent, edematous interstitium at C5a injection sites. In some instances leukocytoclasis was present (Fig. 5). Endothelial cells at these sites were swollen, rounded, and pale; fibrin was frequently present about involved vessels. Differential counts of perivascular leukocytes revealed that PMNs accounted for $70 \%$ of the cells in these infiltrates;

Table I. Comparison of In Vivo Intradermal Reactivity of Human C5a With Other Pharmacologic and Endogenous Mediators*

\begin{tabular}{lrll}
\hline & & $\begin{array}{l}\text { Amount of C5a } \\
\text { producing } \\
\text { equivalent } \\
\text { clinical reaction }\end{array}$ & $\begin{array}{l}\text { No. of normal } \\
\text { volunteers tested }\end{array}$ \\
\hline Agent & Dose & $n g$ & \\
Histamine & $1 \mu \mathrm{g}$ & 40 & 2 \\
$48 / 80$ & $400 \mathrm{ng}$ & 20 & 1 \\
Morphine sulfate & $3 \mu \mathrm{g}$ & 20 & 2 \\
Human C3a & $500 \mathrm{ng}$ & 10 & 2 \\
\hline
\end{tabular}

* Data shown in this table relate only to the diameter of wheal and flare reactions at local injection sites. variable percentages of mononuclear cells and eosinophils were also seen in these biopsies (Table II). Tissue samples from 12 volunteers stained with Giemsa revealed mast cell degranulation and free metachromatic granules at $\mathrm{C} 5 \mathrm{a}$ injection sites.

Ten biopsies were performed in eight volunteers to assess the histology of control skin test sites $20 \mathrm{~min}$ after the intradermal injection of sterile saline, ZX-treated saline, or C5 treated with unactivated zymosan. These biopsies could not be distinguished from each other. The perivascular leukocytic infiltrates, mast cell alterations, and dermal edema observed at C5a injection sites were not seen in biopsies of control sites.

To assess the histology of C5a skin test sites at times later than 20 min after injection, biopsies were obtained from 40ng injection sites in two volunteers, 1 and $24 \mathrm{~h}$ after administration of anaphylatoxin. The histologic pattern observed 1 $h$ after $\mathrm{C5a}$ injection consisted of a mild superficial and middermal perivascular, leukocytic infiltrate in association with modest dermal edema. The number of infiltrating leukocytes and the degree of dermal and endothelial cell edema was clearly reduced in comparison to the reaction observed 20 min after intradermal injection of an equivalent amount of $\mathrm{C5a}$ in the same volunteer. An even less intense reaction was seen in the biopsy obtained $24 \mathrm{~h}$ after intradermal injection of C5a. To histologically assess reactions to various amounts of human C5a, one volunteer was injected intradermally with 2 , 6,20 , and $80 \mathrm{ng}$ of anaphylatoxin and then biopsied at each site 20 min later. The intensity and character of the histologic findings at injection sites receiving $>20 \mathrm{ng}$ of $\mathrm{C5a}$ were the same. However, mild upper dermal edema was the only abnormality observed in biopsies of the 2 and $6 \mathrm{ng}$ test sites; perivascular areas in these biopsies were not different from those in control saline injection sites in the same volunteer.

Histopathologic examination of the $\mathrm{C} 5 \mathrm{a}$ continuous infusion site ( $80 \mathrm{ng}$ of $\mathrm{C} 5 \mathrm{a}$ in $0.5 \mathrm{ml}$ administered over $2 \mathrm{~h}$ ) revealed a perivascular, PMN-predominant infiltrate localized to the middermis presumably near the tip of the infusion needle. Endothelial cell swelling was the only alteration observed in blood vessel walls at the $\mathrm{C} 5 \mathrm{a}$ infusion site.

\section{Electron microscopy}

Electron microscopy of skin from C5a injection sites confirmed the presence of the PMN-predominant perivascular, leukocytic 


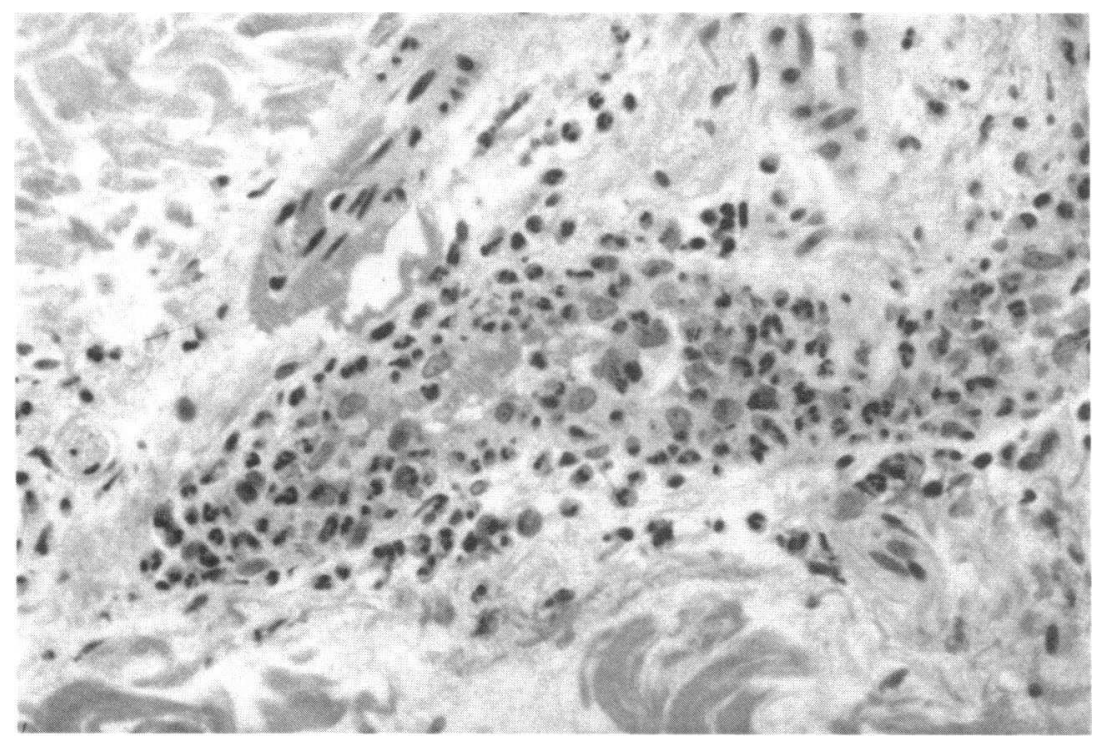

Figure 5. This skin biopsy obtained $20 \mathrm{~min}$ after the intradermal injection of $20 \mathrm{ng}$ of C5a demonstrates a perivascular PMN-predominant infiltrate, associated dermal edema, and thickened blood vessel walls. Neutrophils are seen invading the vessel wall and the adjacent interstitium; in some areas leukocytoclasis is present $(\times 62.5)$. infiltrate observed on light microscopy. In addition, electron microscopy documented mast cell degranulation within 3 min of C5a injection (20 ng). Electron micrographs of this biopsy demonstrated dark nonmembrane-limited mast cell granules just beyond the confines of an intact plasma cell membrane (Figs. 6 and 7). There was clear evidence of mast cell association with an accessory cell as has been reported in rat skin. Other intracytoplasmic, membrane-limited granules in these mast cells were amorphous and lacked their normal lamellae. Electron microscopy of skin test sites 15 and $30 \mathrm{~min}$ after the intradermal injection of $80 \mathrm{ng}$ of $\mathrm{C5a}$ in two volunteers revealed vacuolated and hypogranular mast cells in association with a more dense perivascular leukocytic infiltrate. Electron microscopy of skin from control intradermal injection sites in these same two volunteers revealed intact mast cells with characteristic lamellae and membrane-limited granules.

\section{Pharmacologic modulation of skin reactivity to human $\mathrm{C5a}$}

Two normal volunteers were tested intradermally with $40 \mathrm{ng}$ of C5a before and on the second day of treatment with hydroxyzine. Hydroxyzine produced a significant reduction in flare at C5a skin test sites with only a modest reduction in whealing reactions (Table III). There was no significant difference in the histology of C5a injection sites before and after treatment with hydroxyzine. Two other normal volunteers

Table II. Differential Counts of Infiltrating Leukocytes in Skin Biopsies of C5a Injection Sites (20 ng) in Eight Normal Volunteers

\begin{tabular}{llll}
\hline & Mean & SEM & Range \\
\hline & $\%$ & & $\%$ \\
Neutrophils & 70.15 & \pm 2.10 & $56.5-75.0$ \\
$\begin{array}{l}\text { Eosinophils } \\
\begin{array}{l}\text { Mononuclear } \\
\text { cells }\end{array}\end{array}$ & 6.74 & \pm 2.68 & $0.5-24.6$ \\
\hline
\end{tabular}

were tested intradermally with $40 \mathrm{ng}$ of C5a before and on the fifth day of receiving prednisone, $15 \mathrm{mg}$ per os four times daily. As shown in Table III, prednisone did not alter C5a wheal and flare reactivity. Again, biopsies of C5a skin test sites in these two volunteers before and after treatment with systemic corticosteroids revealed no significant differences by light microscopy.

In contrast to studies in which pharmacologic agents were given systemically, xylocaine and terbutaline were evaluated for their ability to locally modulate skin reactivity to $\mathrm{C5a}$. C5a-induced erythema at a $40 \mathrm{ng}$ test site was completely blocked by pretreating the skin of a normal volunteer with 2 $\mathrm{mg}$ of xylocaine. However, a volunteer pretreated with intradermal terbutaline $(1,2,10$, and $20 \mu \mathrm{g}$ in $0.05 \mathrm{ml})$ immediately before skin tests with $20 \mathrm{ng}$ of $\mathrm{C} 5 \mathrm{a}$ demonstrated wheal and flare reactions at terbutaline treated sites that were identical to reactions observed at untreated C5a injection sites in the same volunteer.

\section{Discussion}

Almost all the data concerning the biologic activities of human C5a have been generated in vitro or in animal studies. Very little is known about the range of specific biologic activities of C5a in any human organ system, including the skin. As part of the immunochemical characterization of a human C5a preparation, Vallota and Müller-Eberhard (18) demonstrated that this anaphylatoxin can cause wheal and flare reactions in human skin when they tested one volunteer. Subsequently, during the characterization of human C4a, Gorski et al. (19) compared the cutaneous wheal and flare reactivity of human $\mathrm{C} 4 \mathrm{a}, \mathrm{C3a}$, and $\mathrm{C5a}$ in a single volunteer and found that the C5-derived anaphylatoxin was clearly the most potent. However, to date there has been no quantitative assessment of the clinical and histologic reactions at test sites in multiple volunteers. Human skin is a convenient organ in which to study the biologic activities of anaphylatoxins, and observations made in such cutaneous studies may be extrapolated to other human organ systems (20). Furthermore, C5a has been thought to play an important role in a number of skin diseases and 


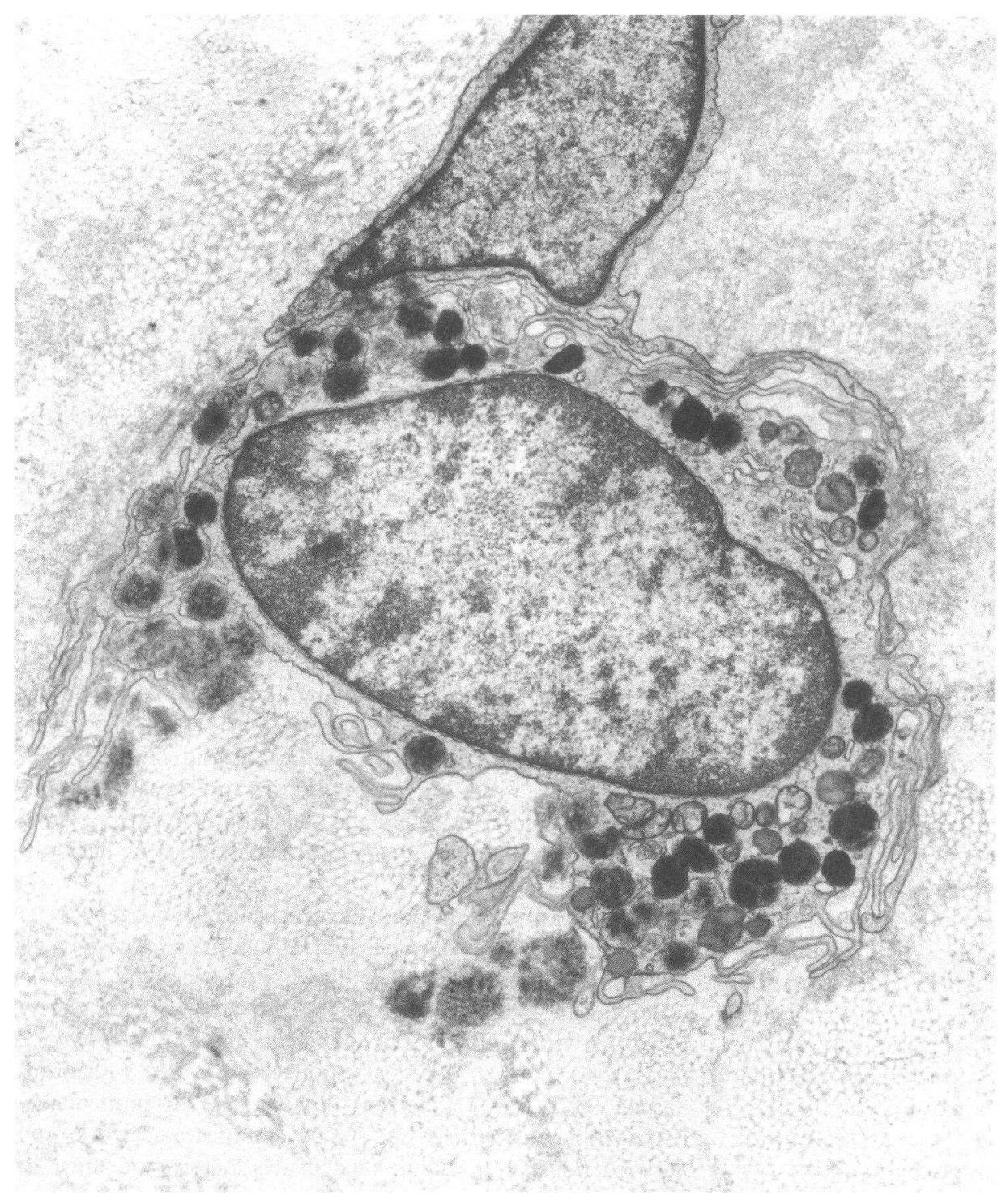

Figure 6. This electron micrograph of skin reveals a degranulating dermal mast cell at a C5a injection site. systemic diseases with cutaneous manifestations. Complement activation and production of $\mathrm{C5a}$ has been felt to contribute to vascular permeability, PMN-predominant infiltrates, and leukocytoclasis observed in lesional skin of patients with necrotizing vasculitis (21). C5a has also been suggested to account for neutrophil-rich infiltrates observed at sites of tissue damage in the bullous eruption of systemic lupus erythematosus, dermatitis herpetiformis, bullous pemphigoid, and herpes gestationis $(9,22,23)$. Recent studies have also shown that complement activation and generation of C5derived chemotactic activity is relevant to lesion formation in patients with erythropoietic protoporphyria, porphyria cutanea tarda, and demethylchlortetracycline-induced phototoxicity $(24,25)$.

To precisely define the in vivo reactivity of human C5a in human skin we examined the effects of skin tests with a wellcharacterized, biologically active C5a preparation. This C5a preparation contained a protein that comigrated with radiolabeled C5a des Arg in SDS PAGE and that stained in immunoblot with an antiserum recognizing human $\mathrm{C5a}$. The specific range of C5a's biologic activity in this study is in general agreement with other observations $(1,2,26)$. This C5a is a potent chemoattractant for neutrophils and monocytes $\left(0.5 \times 10^{-7}\right.$ to $\left.10^{-9} \mathrm{M}\right)$, an inducer of neutrophil myeloperoxidase release (concentrations $\geq 10^{-10} \mathrm{M}$ ), and an aggregator of neutrophils (concentrations $\geq 10^{-10} \mathrm{M}$ ). Additionally, cutaneous reactivity to $\mathrm{C5a}$ was blocked by treating the skin test reagent with an anti-C5a immunoadsorbent but not an anti-C3a immunoadsorbent, also demonstrating that clinical responses were caused by C5a. We found that human C5a, in doses ranging from 1 to $80 \mathrm{ng}$, reproducibly elicits a rapid wheal and flare reaction in human skin that begins within seconds of injection and lasts for 60 to $75 \mathrm{~min}$. The magnitude of the clinical response is clearly dose dependent. Prolonged intradermal infusion resulted in a blunted cutaneous response perhaps due to suboptimal C5a levels in the microenvironment of the infusion site, local tachyphylaxis, or rapid inactivation, degradation, and clearance of $\mathrm{C} 5 \mathrm{a}$ by endogenous proteases or interacting cellular elements.

All concentrations of human C5a tested in this study (2 $\times 10^{-9} \mathrm{M}$ to $\left.1.2 \times 10^{-7} \mathrm{M}\right)$ were well within the potential physiologic range suggested by Hugli et al. (1) and Fernandez et al. (26). Thus, at concentrations that can be achieved in vivo, human $\mathrm{C} 5 \mathrm{a}$ produced immediate clinical and histologic 


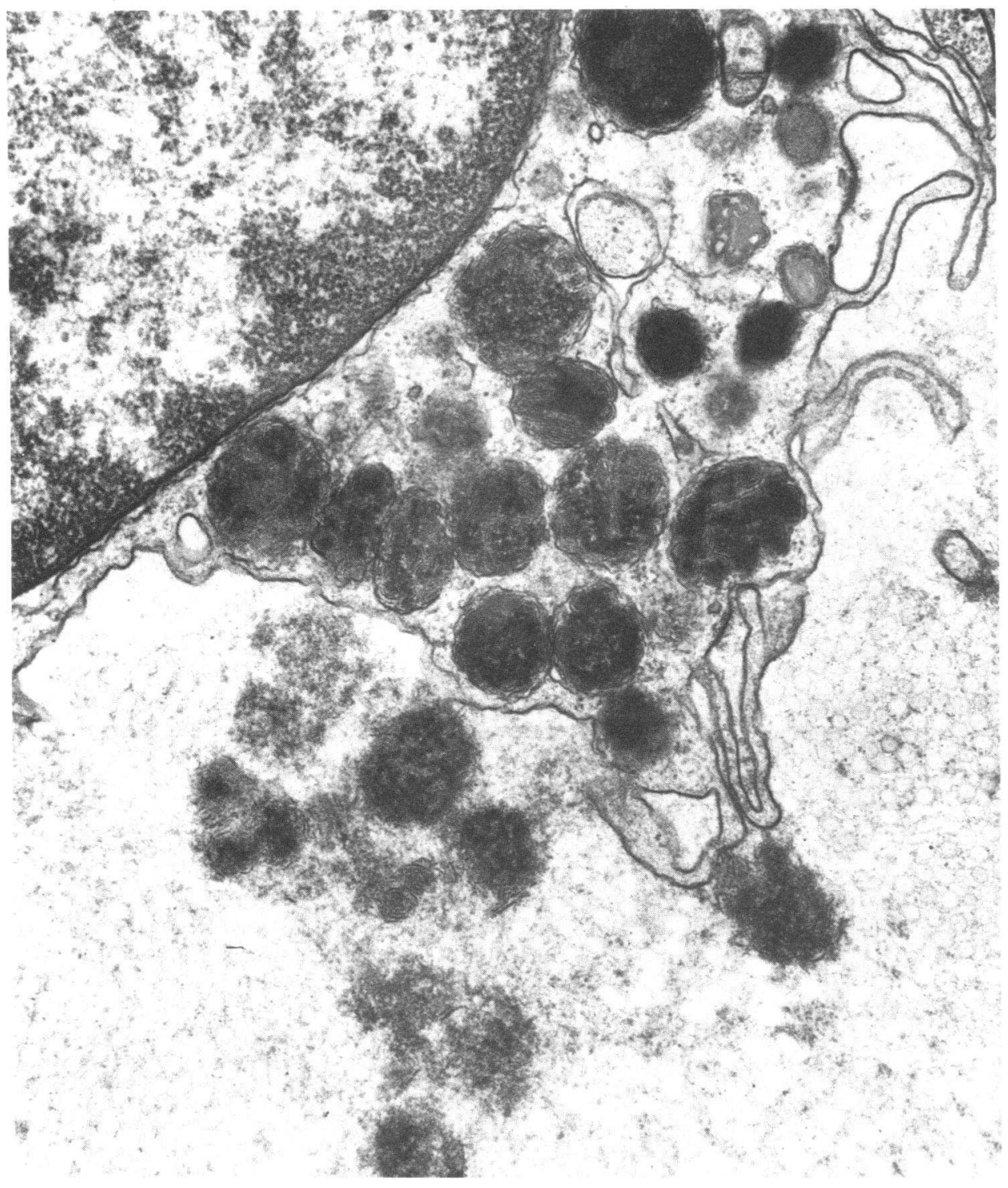

Figure 7. With greater magnification, another degranulating mast cell in an adjacent field of the same specimen described in Fig. 6 demonstrates dark, nonmembrane-limited granules beyond the confines of an intact plasma cell membrane. These changes were not seen in electron micrographs of control injection sites where characteristic mast cell morphology was preserved. reactions in the skin of all subjects tested in this study. When the cutaneous reactivity of human C5a was directly compared with other mediators (human $\mathrm{C} 3 \mathrm{a}$, histamine, 48/80, and morphine sulfate), C5a was the most potent mediator of wheal and flare reactions in this group (wt/wt). C5a was $\sim 50$ times more potent than $\mathrm{C} 3 \mathrm{a}$ and $\sim 25$ times more potent than histamine in producing these reactions. All skin test reactions to C5a, C3a, histamine, $48 / 80$, and morphine sulfate were immediate, lasted no more than 60 to $75 \mathrm{~min}$, and were not associated with palpable purpura, vesicle formation, or later reactions. In this regard these mediators differ from the leukotrienes $B_{4}, C_{4}, E_{4}$, and prostaglandin $D_{2}$, which produce more prolonged and in some instances delayed onset reactions following intradermal injection (27).

Biopsies from skin test sites $20 \mathrm{~min}$ after the intradermal injection of $20 \mathrm{ng}$ (or more) of C5a revealed a PMN-predominant, superficial and mid-dermal perivascular leukocytic infiltrate sometimes associated with leukocytoclasis. Blood vessels at these injection sites contained intramural leukocytes and endothelial cells that were rounded, pale, and swollen. Electron microscopy revealed that C5a caused mast cell degranulation within minutes of injection and that mast cells at skin test sites were vacuolated and hypogranular $15 \mathrm{~min}$ after intradermal administration of anaphylatoxin. Furthermore, direct RIA of histamine in suction blister fluids from C5a and control injection sites demonstrated $>10$-fold higher levels of this mast cell-derived mediator overlying skin tested with anaphylatoxin (data not shown). Biopsies obtained from injection sites at various time intervals after C5a injection revealed that histologic alterations at these skin test sites began within $3 \mathrm{~min}$, peaked within $30 \mathrm{~min}$, and were clearly reduced in intensity $1 \mathrm{~h}$ after anaphylatoxin administration. There was no histologic evidence of frank necrotizing vasculitis or late phase reactions at any C5a injection site in this study.

Several different pharmacologic agents in doses commonly used to treat urticaria or hypersensitivity problems were tested for their ability to modulate skin reactivity to $\mathrm{C5a}$ in vivo. Although hydroxyzine did reduce erythema at $\mathrm{C} 5 \mathrm{a}$ injection sites (as did local pretreatment of skin with xylocaine), there was no difference in the histology of C5a injection sites in volunteers tested before and after treatment with this $\mathrm{H}_{1}$ antihistamine. Moderate doses of systemic corticosteroids had no effect whatsoever on clinical or histologic reactions at C5a skin test sites. Local pretreatment of $\mathrm{C} 5 \mathrm{a}$ skin test sites with 
Table III. Pharmacologic Modulation of Skin Reactivity to Human C5a

\begin{tabular}{|c|c|c|c|c|c|}
\hline \multirow[b]{2}{*}{ Injection agent } & \multirow{2}{*}{$\begin{array}{l}\text { Minutes after } \\
\text { I.D. injection }\end{array}$} & \multicolumn{2}{|l|}{ Untreated } & \multicolumn{2}{|l|}{ Treated } \\
\hline & & Wheal & Flare & Wheal & Flare \\
\hline & & $m m$ & $m m$ & $m m$ & $m m$ \\
\hline \multicolumn{6}{|l|}{ Hydroxyzine* } \\
\hline & 5 & $11.0 \pm 1.00$ & $47.5 \pm 2.50$ & $9.5 \pm 0.50$ & $14.0 \pm 2.00$ \\
\hline & 10 & $10.5 \pm 1.05$ & $57.5 \pm 12.50$ & $9.0 \pm 0.00$ & $15.5 \pm 2.50$ \\
\hline & 15 & $11.5 \pm 2.50$ & $57.5 \pm 12.50$ & $9.0 \pm 0.00$ & $16.0 \pm 3.00$ \\
\hline & 25 & $11.5 \pm 2.50$ & $50.0 \pm 5.00$ & $9.5 \pm 0.50$ & $16.5 \pm 3.50$ \\
\hline \multicolumn{6}{|l|}{ Prednisoneł } \\
\hline & 5 & $11.5 \pm 0.50$ & $60.0 \pm 0.00$ & $10.0 \pm 0.00$ & $42.5 \pm 7.50$ \\
\hline & 10 & $13.5 \pm 1.50$ & $67.5 \pm 2.50$ & $11.5 \pm 0.50$ & $62.5 \pm 12.50$ \\
\hline & 15 & $14.0 \pm 2.00$ & $67.5 \pm 2.50$ & $13.5 \pm 2.50$ & $75.0 \pm 0.00$ \\
\hline & 25 & $14.0 \pm 2.00$ & $65.0 \pm 5.00$ & $13.5 \pm 2.50$ & $55.0 \pm 10.00$ \\
\hline
\end{tabular}

* Mean wheal and flare diameter at various time intervals after the intradermal (I.D:) injection of $20 \mathrm{ng}$ of C5a in two normal volunteers before and after treatment with hydroxyzine $(50 \mathrm{mg}$ per os twice daily $\times 2 \mathrm{~d}$ ). ‡ Mean wheal and flare diameter at various time intervals after the I.D. injection of $20 \mathrm{ng}$ of $\mathrm{C} 5 \mathrm{a}$ in two normal volunteers before and on the fifth day of receiving prednisone, $15 \mathrm{mg}$ per os four times a day.

terbutaline was included in this series of experiments because it has been shown that as little as $1 \mu \mathrm{g}$ of this agent will reduce antigen specific skin test reactivity in known allergen-sensitive subjects (28). However, local administration of as much as 20 $\mu \mathrm{g}$ of terbutaline before intradermal testing with C5a did not alter subsequent wheal and flare reactions in controlled injection studies.

This study has defined in detail the cutaneous reaction pattern to $\mathrm{C5a}$ in man and demonstrated that $\mathrm{C5a}$ is a potent mediator of inflammation in human skin in vivo. It confirms and extends observations previously made in animals and in vitro, and suggests that this soluble mediator may be a valuable in vivo probe for the investigation of the pathophysiology of immunologically mediated skin disorders and systemic diseases with cutaneous manifestations.

\section{Acknowledgments}

The authors thank Ms. Gabrielle Neises and Ms. Donna Stivers for the electron microscopy studies reported in this manuscript, and Ms. Lois Feinstein and Mr. Harry Schaefer for the preparation of this manuscript and its illustrations. Dr. Michael Kaliner kindly performed RIAs of histamine levels in suction blister fluids that were reported in this study.

\section{References}

1. Hugli, T. E., and H. J. Müller-Eberhard. 1978. Anaphylatoxins: C3a and C5a. Adv. Immunol. 26:1-53.

2. Hugli, T. E. 1981. The structural basis for anaphylatoxin and chemotactic function of $\mathrm{C} 3 \mathrm{a}, \mathrm{C} 4 \mathrm{a}$, and $\mathrm{C5a}$. CRC Crit. Rev. Immunol. 2:321-366.

3. Webster, R. O., G. L. Larsen, and P. M. Henson. 1982. In vivo clearance and tissue distribution of $\mathrm{C} 5 \mathrm{a}$ and $\mathrm{C} 5 \mathrm{a}$ des Arginine complement fragments in rabbits. J. Clin. Invest. 70:1177-1183.

4. Goodman, M. B., D. E. Chenoweth, and W. O. Weigle. 1982. Potentiation of the primary humoral immune response in vitro by C5a anaphylatoxin. J. Immunol. 129:70-75.

5. Morgan, E. L., M. L. Thoman, W. O. Weigle, and T. E. Hugli. 1983. Anaphylatoxin-mediated regulation of the immune response. II. C5a-mediated enhancement of human humoral and $T$ cell-mediated immune responses. J. Immunol. 130:1257-1261.
6. Jose, P. J., M. J. Forrest, and T. J. Williams. 1981. Human C5a des Arg increases vascular permeability. J. Immunol. 127:2376-2380.

7. Hugli, T. E., and D. E. Chenoweth. 1980. Biologically active peptides of complement: techniques and significance of $\mathrm{C3a}$ and $\mathrm{C5a}$ measurements. In Future Perspectives in Clinical Laboratory Immunoassays. R. M. Nakamura, W. R. Dito, and E. S. Tucker, editors. Alan R. Liss Inc., New York. 448-467.

8. Hammerschmidt, D. E., L. J. Weaver, L. D. Hudson, P. R. Craddock, and H. S. Jacob. 1980. Association of complement activation and elevated plasma-C5a with adult respiratory distress syndrome: pathophysiological relevance and possible prognostic value. Lancet. I: 947-949.

9. Hall, R. P., T. J. Lawley, H. R. Smith, and S. I. Katz. 1982. Bullous eruption of systemic lupus erythematosus: dramatic response to dapsone therapy. Ann. Intern. Med. 97:165-170.

10. Lawley, T. J., and R. P. Hall. 1981. Circulating immune complexes in dermatologic disease. Springer Semin. Immunopath. 4: 221-240.

11. Hammer, C. H., G. H. Wirtz, L. Renfer, H. D. Gresham, and B. F. Tack. 1981. Large scale isolation of functionally active components of the human complement system. J. Biol. Chem. 256:3995-4006.

12. Laemmli, U. K. 1970. Cleavage of structural proteins during the assemby of the head of bacteriophage $T_{4}$. Nature (Lond.). 277: 680-685.

13. Harvath, L., W. Falk, and E. J. Leonard. 1980. Rapid quantitation of neutrophil chemotaxis: use of a polyvinylpyrrolidone-free polycarbonate membrane in a multiwell assembly. J. Immunol. Methods. 37:39-45.

14. Boyum, A. 1962. Isolation of mononuclear cells and granulocytes from human blood. Scand. J. Clin. Lab. Invest. Suppl. 21:77-89.

15. Falk, W., R. H. Goodwin, and E. J. Leonard. 1980. A 48-well micro chemotaxis assembly for rapid and accurate measurement of leukocyte migration. J. Immunol. Methods. 33:239-247.

16. Webster, R. O., and P. M. Henson. 1978. Rapid micromeasurement of neutrophil exocytosis. Inflammation. 3:129-135.

17. Hammerschmidt, D. E., T. K. Bowers, C. J. Lammi-Keffe, H. S. Jacob, and P. R. Craddock. 1980. Granulocyte aggregometry: a sensitive technique for the detection of C5a and complement activation. Blood. 55:898-902.

18. Vallota, E. H., and H. J. Müller-Eberhard. 1973. Formation of C3a and C5a anaphylatoxins in whole human serum after inhibition of the anaphylatoxin inactivator. J. Exp. Med. 137:1109-1123.

19. Gorski, J. P., T. E: Hugli, and H. J. Müller-Eberhard. 1979. 
C4a: the third anaphylatoxin of the human complement system. Proc. Natl. Acad. Sci. USA. 76:5299-5302.

20. Wuepper, K. D., V. A. Bokish, H. J. Müller-Eberhard, and R. B. Stoughton. 1972. Cutaneous responses to human C3 anaphylatoxin in man. Clin. Exp. Immunol. 11:13-20.

21. Lawley, T. J., and M. M. Frank. 1980. Immune complexes and immune complex diseases. In Clinical Immunology, Vol. 1. C. W. Parker, editor. W. B. Saunders Co., Philadelphia, PA. 143-172.

22. Atkinson, J. P., and M. M. Frank. 1980. Complement. In Clinical Immunology, Vol. 1. C. W. Parker, editor. W. B. Saunders Co., Philadelphia, PA. 219-271.

23. Katz, S. I., and T. T. Provost. 1979. Herpes gestationis. In Dermatology in General Medicine. T. B. Fitzpatrick, A. Z. Eisen, K. Wolf, I. M. Freedberg, and K. F. Austen, editors. McGraw-Hill, New York. Second ed. 324-326.

24. Lim, H. W., H. D. Perez, M. B. Poh-Fitzpatrick, I. M.
Goldstein, and I. Gigli. 1981. Generation of chemotactic activity in serum from patients with erythropoietic protoporphyria and porphyria cutanea tarda. N. Engl. J. Med. 304:212-216.

25. Lim, H. W., H. Novotny, and I. Gigli. 1983. Role of complement and polymorphonuclear cells in demethylchlortetracycline-induced phototoxicity in guinea pigs. J. Clin. Invest. 72:1326-1335.

26. Fernandez, H. N., P. M. Henson, A. Otani, and T. E. Hugli. 1978. Chemotactic response to human $\mathrm{C} 3 \mathrm{a}$ and $\mathrm{C} 5 \mathrm{a}$ anaphylatoxins. I. Evaluation of C3a and C5a leukotaxis in vitro and under simulated in vivo conditions. J. Immunol. 120:109-115.

27. Soter, N. A., R. A. Lewis, E. J. Corey, and K. F. Austen. 1983. Local effects of synthetic leukotrienes $\left(\mathrm{LTC}_{4}, \mathrm{LTD}_{4}, \mathrm{LTE}_{4}\right.$, and $\left.\mathrm{LTB}_{4}\right)$ in human skin. J. Invest. Dermatol. 80:115-119.

28. Grönneberg, R., and K. Strandberg. 1981. Effect of terbutaline on cutaneous responses in man to rechallenge with allergen and compound 48/80. Allergy (Copenh.). 36:33-38. 